Helgoländer wiss. Meeresunters. 30, 47-61 (1977)

\title{
Ecological studies on the deep-water pelagic community of Korsfjorden (western Norway)
}

\section{The search for a trophic pattern}

\author{
J. B. L. Matthews \& J. L.W. Bakke \\ Biological Station, University of Bergen; Bergen, Norway
}

\begin{abstract}
As part of a project aimed at assessing the available energy in a pelagic system and the efficiency of its transfer, monthly biomass estimates of the 23 main macroplanktonic and mesoplanktonic species have been made in Korsfjorden (Norway). Sampling was carried out over approximately 3 years (1971-1974) and results are presented as mg dry weight in a $690 \mathrm{~m}^{3}$ water column. The total annual stocks of the various species were not constant in the 3 years of sampling. Principal components analyses of the monthly stocks in each of the 3 years show striking differences in the correlation matrices from year to year. On the basis of known and supposed feeding habits, the species have been classified as herbivores, omnivores, or carnivores. The monthly biomass estimates of these groups show a consistent pattern from year to year. This, in contrast to the variable correlations between individual species, indicates that there can be considerable flexibility in the specific composition of a planktonic community without correspondingly marked effects on its trophic structure.
\end{abstract}

\section{INTRODUCTION}

One of the major problems in studies of pelagic productivity concerns the availability of energy and the efficiency of its transfer within the community. In view of the dominance of Calanus species in many temperate areas where advanced plankton studies have been carried out, one is tempted to treat total zooplankton as being synonymous with secondary production, i.e. as being composed exclusively of herbivores providing the necessary link between primary producers and the nektonic and benthonic carnivores. Many planktonic communities, however, have a considerable carnivorous component which must surely involve much cycling of organic material within the community and reduce the energy available to dependent communities.

Examples of this type of community are found in the depths of Norwegian fjords, well below the euphotic zone. The proximity of Korsfjorden to the Biological Station, University of Bergen, led to the choice of this site for elucidating the trophic dynamics of a community, as represented by the stock present in a water column $1 \mathrm{~m}^{2}$ in crosssection. The fjord has a complicated topography. The main basin is $690 \mathrm{~m}$ deep and the offshore sill lies at approximately $250 \mathrm{~m}$. Around Korsfjorden are numerous 
branch fjords, each with its own sill, and there are also numerous narrow sounds connecting with the sea through an archipelago. A large landward extension of the same fjord system is separated from the main basin of Korsfjorden by a sill at about $400 \mathrm{~m}$ depth. The fjord is well oxygenated at all times and contains an oceanic water type, apparently of Atlantic origin, under a surface layer of lower salinity (see Matthews \& Sands, 1973, for a description of the fjord and its hydrography and of the sampling programme).

Tackling the problem involved a period of quantitatively sampling the community with special emphasis on the various carnivores and, where possible, of the organisms likely to be their main prey. These samples provided data for detailed population analyses which, with the help of calorimetric and biochemical determinations and experimental studies on feeding and assimilation, provided estimates of the energy flux expressed in units common to all populations. Such a detailed study of a community, whose hydrographic environment can be closely monitored, affords an opportunity to obtain estimates of the parameters necessary to elucidate the trophic dynamics of the community on the natural scale rather than in the laboratory or in enclosed ecosystems (cf. Strickland, 1967).

In this paper we take a preliminary look at the main populations to see whether they evince any trophic pattern in their mutual relationships, in order to obtain guidelines for further integration of the populations into the community as it has been sampled. It should be noted that primary production and grazing fall outside the scope of the project in its present form and that important sections of the community occur within the microzooplankton and the nekton, neither of which are included in this study.

\section{MATERIAL AND METHODS}

The results presented here are based on material collected fortnightly in Korsfjorden $\left(60^{\circ} 12^{\prime} \mathrm{N}, 5^{\circ} 14^{\prime} \mathrm{E}\right)$ with two different sampling devices. The Longhurst Frame net (LF) - mouth diameter $33 \mathrm{~cm}$, length $1 \mathrm{~m}$, and mesh aperture $0.5 \mathrm{~mm}$ - was used to sample all species of copepods during the period February 1971 to February 1974. This net is designed to hold the Longhurst-Hardy serial plankton sampler (Benthos Inc.) but was used here with a simple cod-end and a time-depth recorder. The LF hauls were taken obliquely from near the bottom at $690 \mathrm{~m}$ to the surface. The 12 species in the other animal groups were collected in the period February 1971 to October 1973 using Beyer's low-speed midwater trawl (BLSMT) with mouth opening $1 \mathrm{~m}^{2}$, length $4 \mathrm{~m}$, and mesh aperture $0.9 \mathrm{~mm}$. BLSMT samples were taken in divided hauls from near the bottom to $250 \mathrm{~m}$ and from $250 \mathrm{~m}$ to the surface.

The various maturity stages of the species were counted and then adjusted, first for any correction necessary for the particular sample and then to represent the stock in the water column $690 \mathrm{~m}$ deep and $1 \mathrm{~m}^{2}$ in cross-section. Monthly averages were taken of these final values in order to reduce the effect of sampling error.

For the copepods, monthly biomass values, expressed as mg dry weight, have been obtained by multiplication of the numerical data by the average dry weight of a representative number of animals at the appropriate copepodid stage. For all other 
species, the length of each individual was measured and the biomass obtained from length/dry weight regression equations established for each species. These equations will be published elsewhere. Only fresh animals were weighed except for Tomopteris belgolandica and T. planktonis.

A computer programme for principal components analysis, BMD 1M (Dixon, 1973), was used in the analysis of the mutual variations in specific biomass. The computer code names have also been used to identify the various species in the figures.

\section{RESULTS}

\section{The community of species}

The sampled populations consisted of 23 species which have been estimated quantitatively (Fig. 1). This does not include the small species which were severely underrepresented in the samples, nor does it include numerous species which occurred sporadically and in small numbers. Such species combined made no significant contribution to the biomass of the samples at any time.

Calanus finmarchicus completely dominates the community. Its biomass is at least an order of magnitude greater than the nearest runners-up, C. byperboreus and Metridia longa. In all three cases, particularly $C$. byperboreus, the annual stocks showed a progressive decrease during the three years of sampling, despite a repeat of the main features of the seasonal cycle each year. All three species are at their lowest ebb in March/April, though not exactly synchronously. Sometimes the recovery in the spring is rapid and goes straight to the maximum for the year, as in the case of C. finmarchicus in 1971; in other years subsequent generations continue to produce an increase in the stock.

Eukrohnia hamata is the only other species to have reached biomass levels in excess of $1 \mathrm{~g}$ dry weight under $1 \mathrm{~m}^{2}$. Though the stock fluctuated quite considerably, there is no regular cycle apart from a tendency towards low values in spring (April).

Boreomysis arctica and Meganyctiphanes norvegica come next in order of stock size. The former also has no clear annual cycle but its stock can vary markedly from year to year. It is a species which has a significant hyperbenthic element in its population, impossible to sample quantitatively in relation to the plankton, so its total stock is certainly underestimated here and a cycle might be more apparent were the whole population sampled. $M$. norvegica, on the other hand, shows a very regular cycle, though recruitment of the new generation varies; it was very poor in 1973. The species has a two-year life span (Matthews, 1973), so the cycle depicted here, involving negligible stocks around April, is greatly influenced by the disappearance, not death, of the adult stock. The recovery later in the year is due both to recruitment of the new generation and to reappearance of the previous one.

Several species, namely Euchaeta norvegica, Calanus belgolandicus, Pasiphaea multidentata, Sergestes arcticus, Eukrobnia batbypelagica, and Chiridius armatus, occur regularly at a stock level of several hundred $\mathrm{mg}$ dry weight in the water column.

Euchaeta norvegica has two generations in the year (Bakke, in press) which 

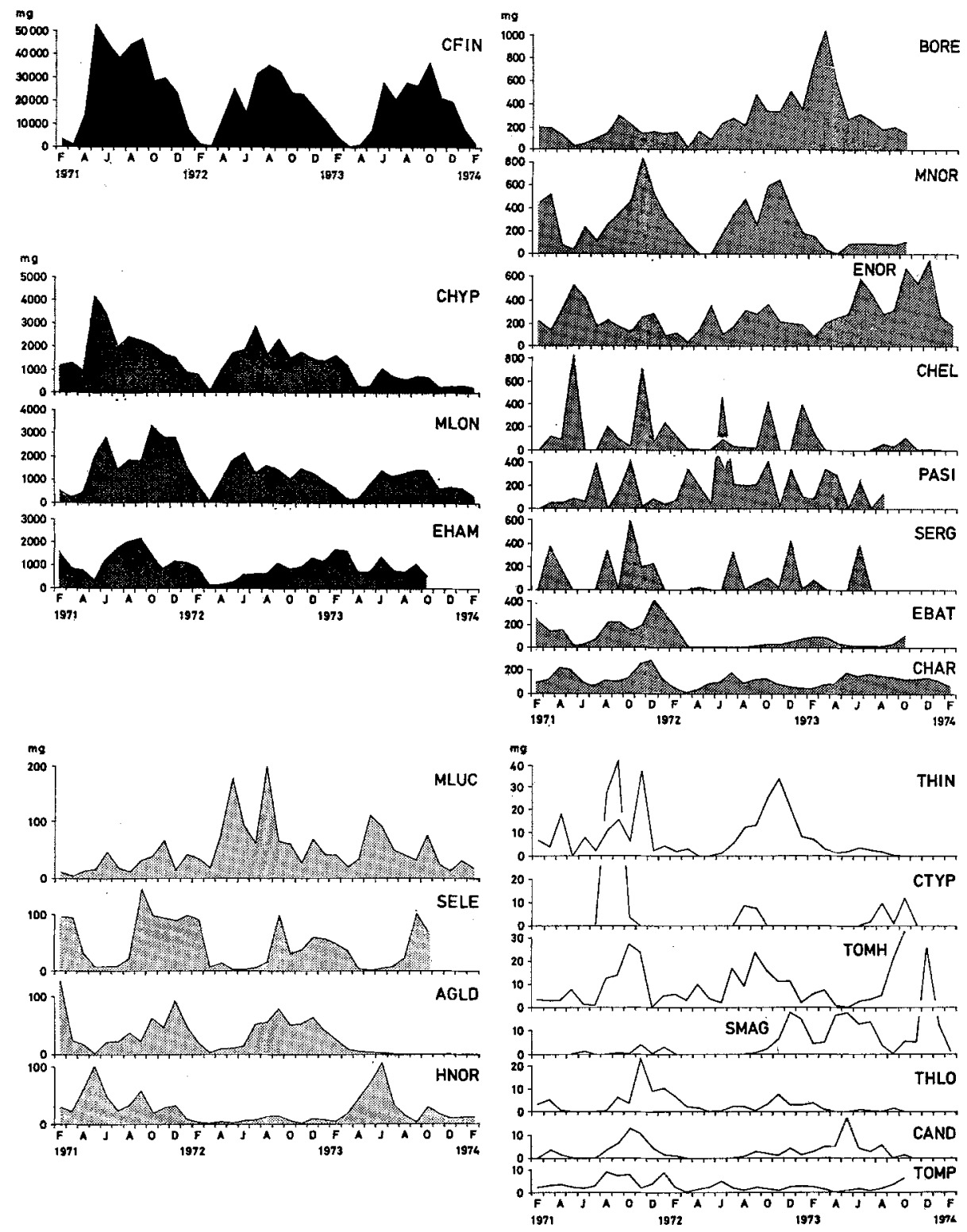

Fig. 1: Estimated monthly biomass of the 23 species, expressed as mg dry weight in the $690-\mathrm{m}$ water column under $1 \mathrm{~m}^{2}$ throughout the period of sampling. Five different scales are used 
are reflected in the generally high values in early summer and early winter. The stocks vary considerably from time to time, possibly due to some extent to sampling error of this species, the largest copepod in the LF samples. The two generations provide recruitment twice a year and the general stock level can therefore vary within years, as in 1971, as well as between years.

Calanus belgolandicus is a post-summer visitor, presumably from warmer regions (see e.g. Matthews, 1969), which can persist for many months after its immigration. The species appears to grow and develop after its arrival in Korsfjorden but it is unlikely that it breeds successfully there; stocks are severely depleted or more usually absent in early summer when recruitment from the overwintering stock would be expected to show. The wide fluctuations are almost certainly artifacts of sample analysis; C. belgolandicus is morphologically so similar to C. finmarcbicus that satisfactory counts are nearly impossible in samples containing many thousands of the latter.

Pasiphaea multidentata and Sergestes arcticus are large, relatively long-lived, pelagic decapods (Matthews \& Pinnoi, 1973) which are rather erratically sampled by the BLSMT. The observed fluctuations are certainly affected by sampling error, but the former species seems to maintain a population of around $200 \mathrm{mg}$ dry weight under $1 \mathrm{~m}^{2}$ and the latter rather less, with a low period between January and May, possibly due to dispersal or to flushing of the basin.

Despite the fact that no other records of Eukrobnia batbypelagica have yet been published from the eastern Atlantic Ocean, this species is a regular constituent of the Korsfjord community (identification has been confirmed by Dr. Alvariño, in litt.). The population is subject to some seasonal fluctuations, in particular a variable period of scarcity centred on May and June, and there are marked differences in the annual stocks; that of 1973 was a quarter of 1972. Nevertheless, it does appear to be a species which breeds in the deep basin.

Chiridius armatus breeds twice a year (Bakke, personal communication) with peaks of adults occurring in early summer and early winter, but the stocks become more depleted in late winter. An average stock of only 90 to $140 \mathrm{mg}$ dry weight is contained in the water column.

The next species, Metridia lucens, may be relatively under-represented in the samples due to escape of adults and Stage V copepodids through the LF net. Interpretation of the fluctuations must await a population analysis, but it can clearly be seen that the species achieves different levels of abundance in different years.

Sagitta elegans is a chaetognath which shows clear-cut fluctuations. From March/ April to August it is almost absent from the plankton, but it maintains a stock of around 50 to $100 \mathrm{mg}$ dry weight under $1 \mathrm{~m}^{2}$ for the rest of the year. As the specimens obtained in the plankton samples are very uniform in size and maturity Stages II and III (Thomson, 1947) predominate, it is deduced that the fluctuations in stock size are associated with a breeding cycle; there is evidence from sledge samples that numerous specimens are at times to be found in the hyperbenthos (Oug, personal communication).

Aglantha digitale is a more conspicuous member of the plankton than the small values for dry weight would suggest. It certainly occupies an important place in the trophic dynamics of the community. It is subject to a seasonal cycle which reaches its 
nadir in March or May and builds up gradually until late in the year before again crashing. In 1973 the stock seems to have failed entirely. It is known as an oceanic species (Russell, 1953), but it appears nevertheless to breed and develop within Korsfjorden (Rasmussen, 1971).

Heterorbabdus norvegicus maintains a small population in Korsfjorden. It does not seem to be subject to wide fluctuations resulting from high breeding activity, but the stocks do vary between years; 1972 was a poor year when there appears to have been a failure in recruitment around May and June. A population analysis is necessary to resolve the question whether the increases seen in those two months in 1971 and 1973 are the result of new generations appearing; it is known that surprisingly few juveniles of this species have ever been found in the Korsfjord samples.

The rest of the species included here contribute very little to the biomass of the community, at least in the years sampled.

Thysanoessa inermis, a species with a clear one-year life cycle in Korsfjorden (Jörgensen \& Matthews, 1975), builds up a stock of some $30 \mathrm{mg}$ dry weight under $1 \mathrm{~m}^{2}$ in the autumn; even that failed in 1973, at least up to October.

Centropages typicus is a neritic epiplanktonic species which is probably underrepresented on account of its small size. It only occurs in the plankton during the summer and early autumn when surface temperatures are near the maximum, but it is likely nevertheless to be a resident rather than an immigrant.

Tomopteris belgolandica is a regular but variable species. As with many other species the early months of the year carry small stocks, but in this species the tendency is for the population to remain small for a full six months, from December or January to June, July, or even August, before starting to increase. Though Tomopteris is the most difficult of the present genera for the estimation of dry weight from measurements of individuals, the use of fixed material instead of fresh cannot have affected the results drastically.

Relatively little is known about Scaphocalanus magnus. It has been considered a resident of deep Norwegian fjords and the samples from 1973 seem to support this opinion. The data from 1971 and 1972, on the other hand, demonstrate that the stocks can fall below the level of detection. The population may need external support to maintain itself.

Thysanoessa longicaudata is the third species of euphausiid which occurs regularly in the Korsfjord samples, though the stock is always small, building up to some extent in the autumn.

Candacia norvegica seems to be a visitor in Korsfjorden. In 1971 and 1972 it appeared in the late summer, but in 1973 it reached a peak in May and was present through to November; some local recruitment may have occurred as young juveniles were recorded.

Tomopteris planktonis occurs regularly in the samples but in small numbers. Since its small size and flexible body may result in considerable escaping through the net, the species may deserve better than last place in the biomass table. As in the case of $T$. helgolandica, uncertainty hangs over the dry weight estimations, but despite this $T$. planktonis can hardly occupy an important place in the food web of Korsfjorden. 


\section{Principal components analyses \\ and correlation coefficients}

The seasonal cycles of most of the species can most easily be separated between March and April when stocks tend to be lowest. The monthly stocks for each 12-month period beginning in April have been pooled to give an expression for the size of the stock during that period. Sampling with the LF net continued for eleven months in the period beginning April 1973; March 1974, the missing month, has been allowed for by repeating the February value. Sampling with the BLSMT came to an end ear-

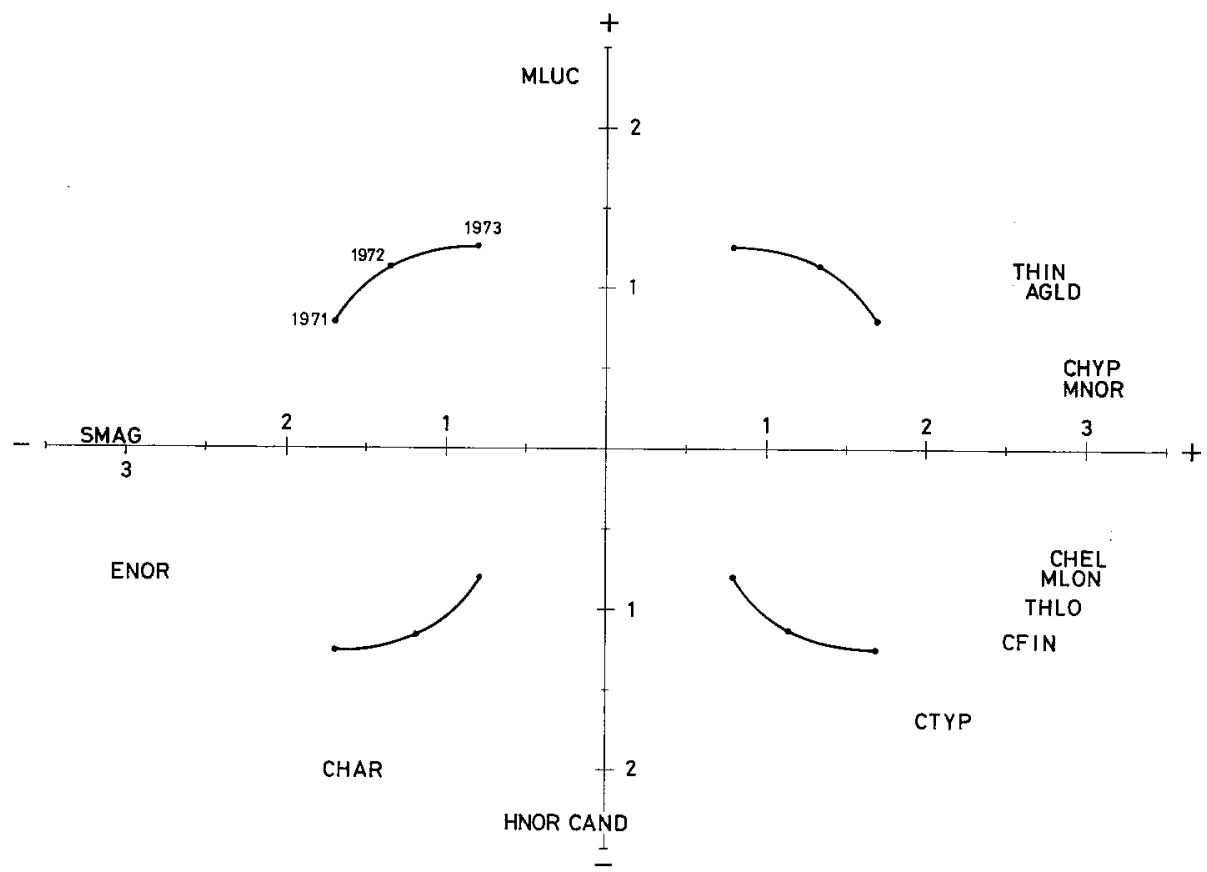

Fig. 2: Results of a principal components analysis of the year to year variation for 15 species. The component loadings are plotted in two dimensions. The curves in each quadrant depict the year to year variation typical of that quadrant

lier; the missing five months have been allowed for by calculating the mean ratio in the first two periods of the twelve monthly values to those from the first seven months and then applying this as a correction factor to the sum of the seven monthly values actually obtained for April to October 1973.

Analysis of the three yearly stocks (15 species have been included) yields the latent vectors which completely describe the total variance in two dimensions (Fig. 2). The positions of the points illustrate the direction of the changes in stock size from year to year, but they do not reflect the extent of these changes since the variance has been standardized for each species in the analysis. The majority of species decreased in the course of the field sampling, some more rapidly between 1971 and 1972 (bottom 
right), others more rapidly between 1972 and 1973 (top right). Diametric opposition in this figure indicates opposite trends in change over the 3 years.

Seasonal cycles are the most obvious part of the variation in the stocks, but the years cannot easily be combined to give average monthly values, in view of the differences between them. Instead, correlations between all pairs of species have been calculated for each of the 3 periods beginning in April 1971, April 1972, and April 1973, respectively. The third period covers only the 7 months actually sampled with both nets, as 5 monthly values are too many to obtain by extrapolation. The results are presented as 3 matrices (Fig. 3) for comparison. There is some tendency towards

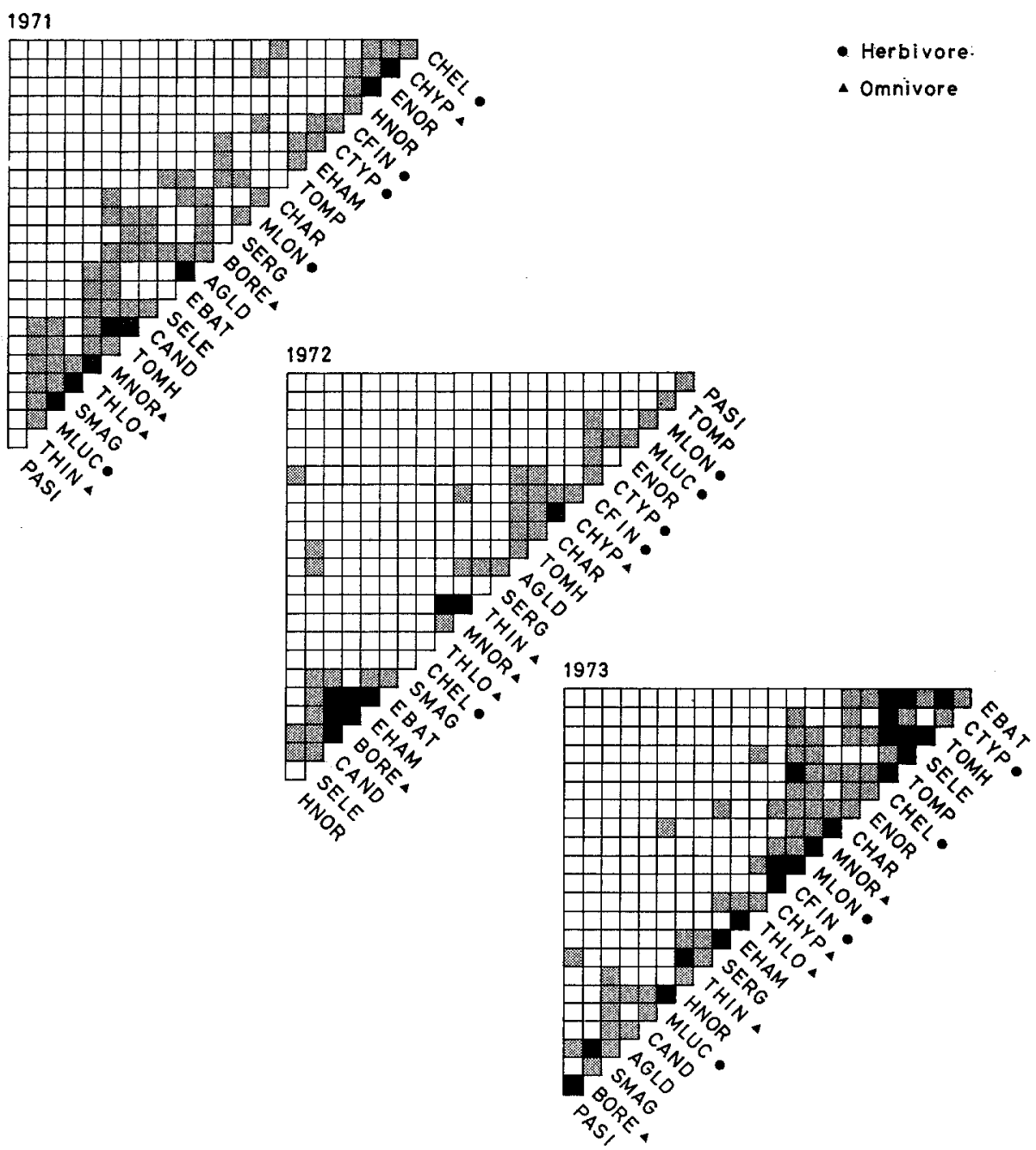

Fig. 3: Correlation matrices of the monthly biomass values for the 23 species in 1971, 1972 and 1973. Black squares indicate correlation coefficients of 0.80 or better, and shaded squares indicate coefficients between 0.50 and 0.79 
grouping and most of the copepods occur in one half of the matrix, the upper half as the species are arranged here. The most obvious feature of the 3 arrangements, however, is their dissimilarity. Metridia lucens, Sagitta elegans, Eukrohnia batbypelagica and Tomopteris spp. are particularly striking examples of this, but also in less extreme cases is there little sign of a consistent pattern from year to year.

These comparisons have been made on a synchronous time scale for all species, and the matrices emphasize positive relationships rather than negative ones. Any effect which one species may have on another, a predation effect for example, can be expected to operate with a time lag. Calculation of correlation coefficients has therefore been repeated with 12 advances of the monthly time scale for the second species in each pair relative to the first. In this way, all possible juxtapositions of the cycles are

Table 1

The 23 species grouped according to their supposed trophic position

\begin{tabular}{|c|c|}
\hline $\begin{array}{l}\text { He r b i vores: } \\
\text { Calanus finmarchicus } \\
\text { C. belgolandicus } \\
\text { Centropages typicus } \\
\text { Metridia longa } \\
\text { M. lucens } \\
\text { Om n i or es : } \\
\text { Calanus hyperboreus } \\
\text { Boreomysis arctica } \\
\text { Meganyctiphanes norvegica } \\
\text { Thysanoessa inermis } \\
\text { T. longicaudata }\end{array}$ & $\begin{array}{l}\text { Ca } \mathrm{n} \text { i } \mathrm{v} \text { ores: } \\
\text { Aglantha digitale } \\
\text { Sagitta elegans } \\
\text { Eukrobnia bamata } \\
\text { E. batbypelagica } \\
\text { Tomopteris planktonis } \\
\text { T. helgolandica } \\
\text { Chiridius armatus } \\
\text { Euchaeta norvegica } \\
\text { Scaphocalanus magnus } \\
\text { Heterorbabdus norvegicus } \\
\text { Candacia norvegica } \\
\text { Sergestes arcticus } \\
\text { Pasiphaea multidentata }\end{array}$ \\
\hline
\end{tabular}

compared for each pair of species. The species have been classified, somewhat subjectively, as herbivores, omnivores, and carnivores on the basis of known and supposed feeding habits (Table 1). The herbivores and one omnivore (Calanus byperboreus) have then been made the basis of each comparison in order to find out whether high correlations occur more frequently with possible predators after a time lag than with species unlikely to be predators.

The maximum positive and negative correlations occurring within a time differential of 4 months are presented for the 3 main herbivores and 1 omnivore compared with other herbivores, the omnivores, and the carnivores, provided that the coefficient was at least 0.5 and was not exceeded by values for 5 or 6 month' difference in time, which were considered to be too great to reflect any direct relationship. The results (Fig. 4) are positioned in 4 quadrants, the upper two representing positive correlations, the lower two negative ones, the right-hand quadrants indicating monthly advances of the second species in the comparison and the left-hand ones indicating monthly retardations.

There is a marked tendency for the carnivores to occur later than the herbivores (high values for the top right quadrant, often with their corollaries in the bottom left). This tendency is also present, but less marked, in comparison with other herbiv- 

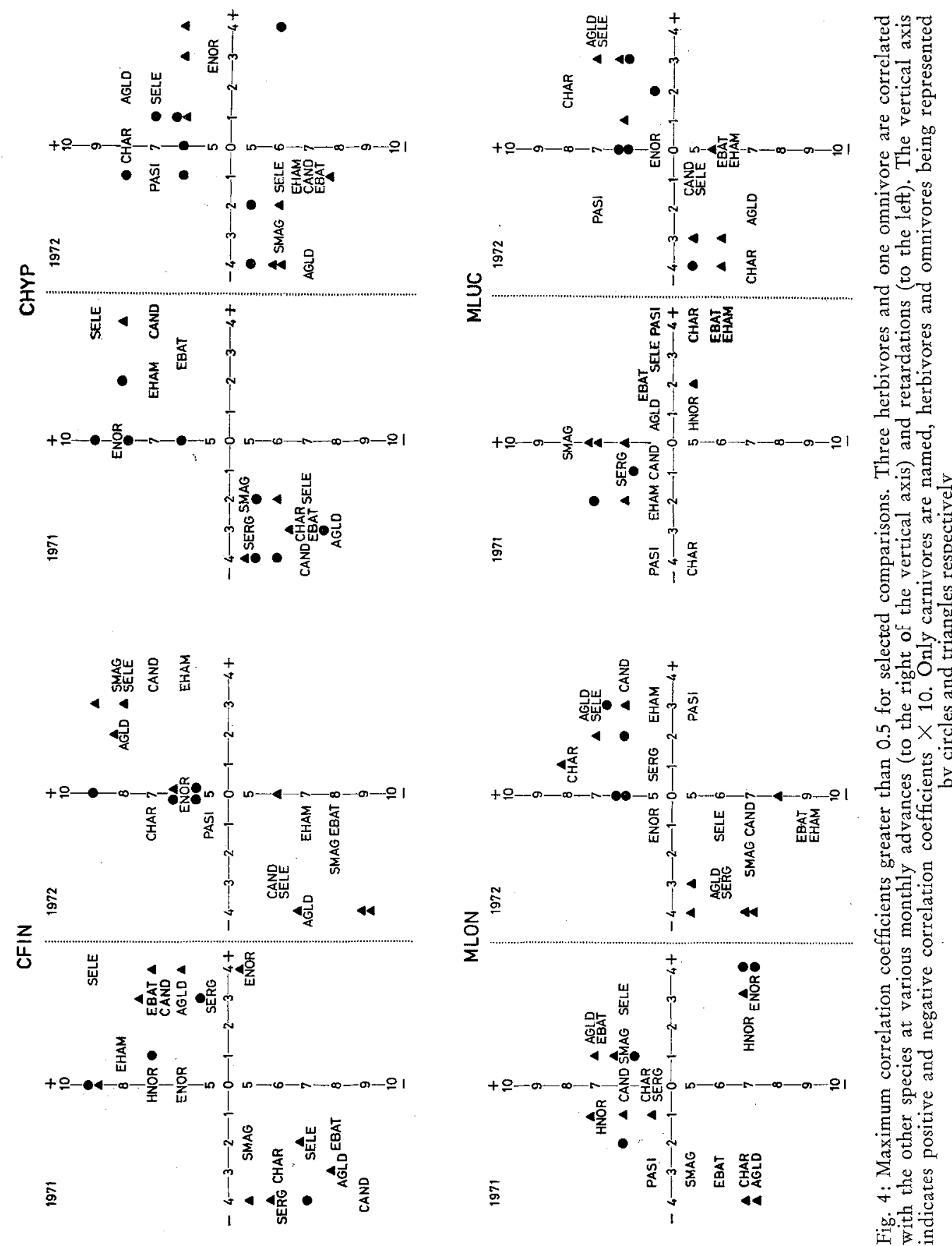
ores and omnivores. This is largely the result of including the omnivores, whose cycles tend to fall later than the herbivores. These (and Calanus finmarcbicus Stage V as a separate entity) were included in order to provide an equal number of comparisons with non-carnivores as with carnivores, not including Tomopteris spp.

Despite this tendency to find the carnivores' cycles delayed in time in relation to the herbivores, there is little constancy in the details observed between 1971 and 1972. Assuming that a time lag is a necessary feature of a direct predator/prey relationship, the only indications from consistencies between 1971 and 1972 are: Calarus finmarchicus may be preyed upon by Aglantba digitale, Candacia norvegica and Sagitta elegans; Metridia longa may be preyed upon by Sergestes arctica, Chiridius armatus, Aglantba digitale and Sagitta elegans; and Metridia lucens may be preyed upon by Sagitta elegans. Since two of these predators, Chiridius armatus and Candacia norvegica, are no larger than their supposed prey, at least the older stages which form the bulk of the biomass of the species, even these indications may be coincidental.

\section{Unstructured trophic levels and their biomass}

The 23 species which comprise the bulk of the mesoplanktonic and macroplanktonic community of Korsfjorden add up to a total biomass which is estimated to vary between 1 and $60 \mathrm{~g}$ dry weight under $1 \mathrm{~m}^{2}$ (Fig. 5). Variation in biomass follows a regular pattern from year to year. There is a brief nadir in March or April followed by a rapid increase. The summer plateau characteristically includes a slight drop after the initial peak in May or June, and values in August-September or even October are generally among the highest in the year. Thereafter, the biomass decreases quite regularly throughout the autumn and winter.

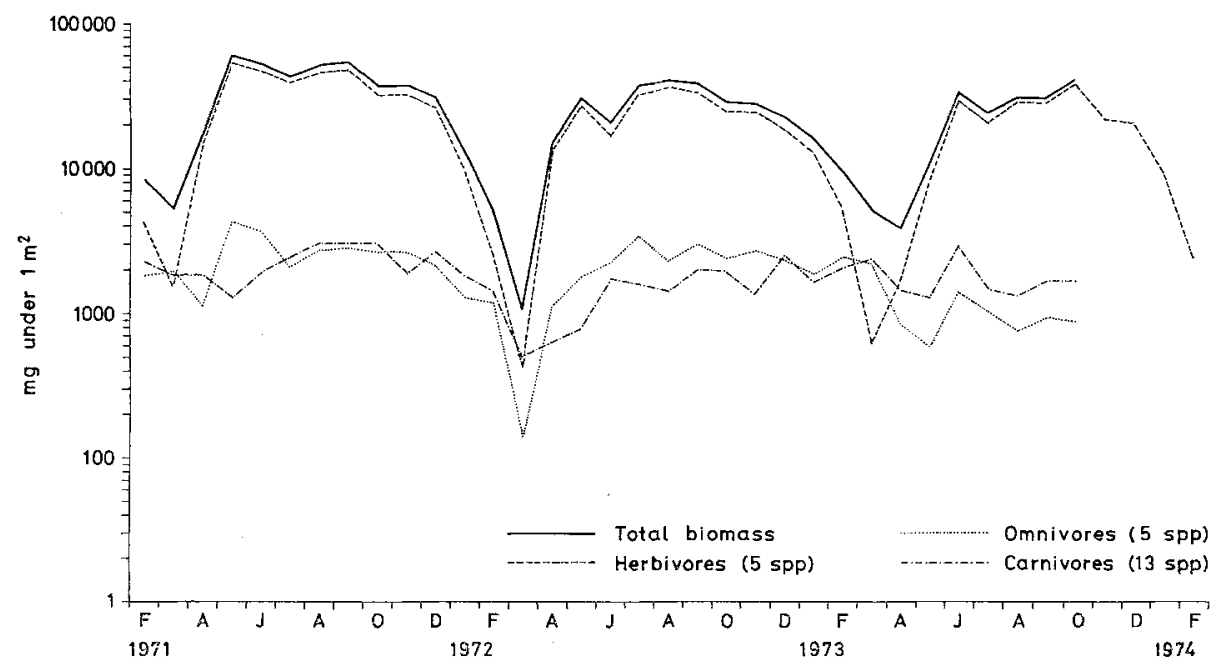

Fig. 5: Monthly estimates of total biomass and of the biomass of herbivores, omnivores and carnivores separately, plotted on a logarithmic scale 
A breakdown of this biomass according to the supposed trophic position of its component species (see Table 1) shows that herbivores are by far the major element and are responsible for the overall pattern. The herbivores, and to a lesser extent the omnivores, exhibit the catastrophic decline in the early months of the year. The carnivores also declined in 1972, but in 1971 and 1973 their decline at this time was no greater than the drop in some other months.

The relative proportions of the 3 groups in the community (Fig. 6) are extremely constant for 9 to 10 months of the year. During the whole of this time carnivores constitute $10 \%$ or less, usually around $5 \%$, of the biomass, compared with 75 to $90 \%$ for the herbivores. For 2 or 3 months, the carnivores assume a more prominent place

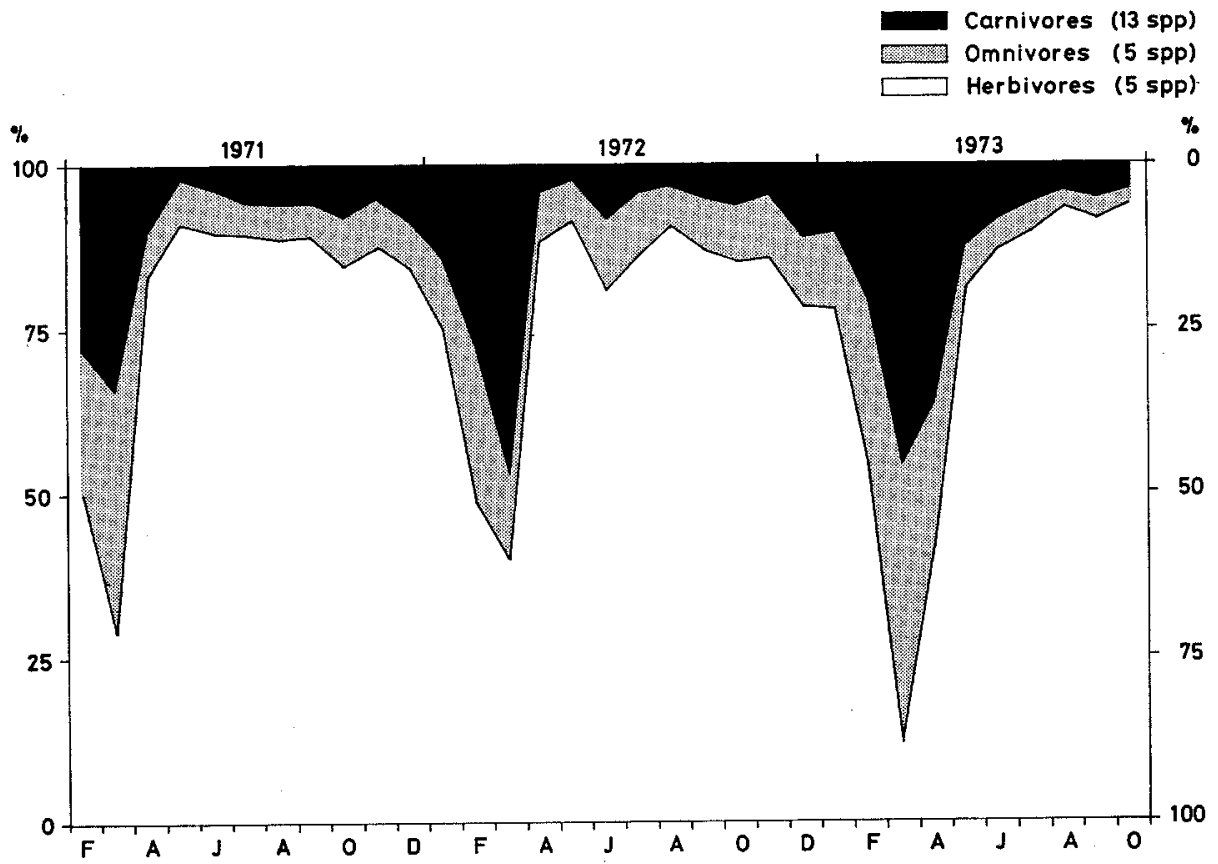

Fig. 6: Percentage composition of the biomass of the sampled community throughout the period of sampling with both nets

in the community - up to nearly half the biomass - at the expense of the herbivores. The omnivores constitute an intermediate area of some uncertainty. Their proportion of the biomass is also relatively constant for most of the year, but increases in autumn and reaches a maximum at or just before the time when the carnivores are at their peak. The dietary constitution of the omnivores is unknown; hence, it is only possible to conclude that the overall relationship between herbivorous and carnivorous feeding lies somewhere within the area which denotes the omnivores. 


\section{DISCUSSION}

The planktonic community is varied but contains no surprises apart from the discovery of Eukrobnia batbypelagica. Neritic, epiplanktonic elements are present, though poorly represented on account of their generally small size. In the deeper layers oceanic species predominate along with some species which thrive in water of oceanic nature but which are perhaps more characteristic of fjords. Water exchange between the deep basin of Korsfjorden is hampered by the presence of sills, but seasonal incursions of such species as Calanus belgolandicus and Candacia norvegica show that exchange does affect the plankton community. Even resident species, in particular Meganyctiphanes norvegica, show fluctuations which are not entirely the result of population changes. The chosen water column does not therefore contain a stationary community and it is clear that environmental effects operate differently at different depths in the column.

It is evident that the main fluctuations in numbers, particularly of herbivores, are the result of intrinsic changes in the populations, i.e. the development, growth, and death of generations. The timing of these changes, within the limits imposed by physiological processes, are supposedly associated with the availability of food. Phytoplankton in Korsfjorden is highly seasonal (Berg, 1973) and this is reflected in the fluctuations in the stock of Calanus finmarchicus. The amplitude of the fluctuations may, however, be only poorly related to the food supply; a period of active growth, encouraged by a good food supply, may embrace a generation in its early stages when biomass is small, while a large biomass may result from the gradual build-up of older individuals with relatively slow growth and a low death rate.

The observed fluctuations in the stocks of the various species are thus the result of the interplay of many different effects, of which food supply is only one. It may, therefore, seem naive to search for predator/prey relationships in correlated changes in the stocks of pairs of species; a much more sensitive probe would seem to be necessary. On the other hand, the consequence of a rigid trophic pattern within the community should be regularity in its composition; particular predator/prey relationships similar to that between Clione limacina and Spiratella spp. (Lalli, 1970) should give consistent correlation coefficients from year to year. In fact, any such consistent relationships are hard to find in Korsfjorden, where the community is quite variable in its specific composition from year to year. This can only mean that there is great trophic flexibility at the species level.

The structure of most natural food webs has conventionally been viewed as extremely complex (see for example Hardy's classic depiction (1924) of the food base for a single predator, the herring). The enormous task of studying trophic dynamics in a pelagic community has been lightened, however, by the recognition that many, if not most, of the predators are opportunists, eating whatever prey of suitable size, consistency, and "catchability" happens to be available (e.g. Marshall \& Orr, 1962; Alverson, 1963; Ponomareva, 1966; and, implicitly, Cosper \& Reeve, 1975).

On this basis, Isaacs (1973) developed the idea that unstructured food webs may be a practical and realistic simplification of natural trophic relationships in the sea. Applying the same reasoning here by grouping the specific biomass data from Kors- 
fjorden according to supposed trophic similarity, a consistent pattern emerges in the balance of the community from year to year. As stated earlier, the sampling methods do not provide a quantitative estimate for more than a limited part of the total size range of organisms. We know nothing of the directly associated variations in primary production or in microzooplankton, which affect the material input to the sampled community, nor do we know anything about the predation pressure from nekton and how this may change in time. Any such changes, however, do not prevent - they may even maintain - cyclical stability in the zooplankton. According to Orians (1975), cyclical stability is often a characteristic feature of predator/prey relationships. The implication in the present case is that the transfer of organic material within the zooplankton falls within limits which can be defined by a predator/prey relationship and, hence, that this "recycling" is reasonably constant. What proportion of the zooplankton goes through more than one trophic step can be estimated once the populational turn-over times have been calculated.

Acknowledgements. Thanks are due to the many people who have contributed to the collection, sorting, and analysis of the plankton samples which provide the basic material for this article. We wish especially to thank L. Hestad for developing programmes capable of handling the large quantity of raw data and converting this to manageable values for biomass, as well as for his help in finding and running suitable programmes for the analysis of the data. We gratefully acknowledge fiancial support granted by the Norwegian Research Council for Science and the Humanities.

\section{LITERATURE CITED}

Alverson, F. G., 1963. The food of yellowfin and skipjack tunas in the eastern tropical Pacific. Bull. inter-Am. trop. Tuna Commn 7, 295-396.

Bakke, J. L. W., 1977. Ecological studies on the deep-water pelagic community of Korsfjorden, western Norway., Population dynamics of Euchaeta norvegica (Crustacea, Copepoda) from 1971 to 1974. Sarsia (In press).

Berg, K.-E., 1974. Overflateplankton i Korsfjorden og Hardangerfjorden 1971-1972. Unpubl. thesis, Univ. Oslo, 195 pp.

Cosper, T. C. \& Reeve, M. R., 1975. Digestive efficiency of the chaetognath Sagitta bispida Conant. J. exp. mar. Biol. Ecol. 17, 33-38.

Dixon, W. J. (Ed.), 1973. BMD. Biomedical computer programs. Univ. California Press, Berkeley, 773 pp.

Hardy, A. C., 1924. The herring in relation to its animate environment. I. The food and feeding habits of the herring with special reference to the east coast of England. Fishery Invest., Lond. (Ser. 2), 7 (3), 1-53.

Isaacs, J. D., 1973. Potential trophic biomasses and trace-substance concentrations in unstructured marine food webs. Mar. Biol. 22, 97-104.

Jörgensen, G. \& Matthews, J. B. L., 1975. Ecological studies on the deep-water pelagic community of Korsfjorden, western Norway. Population dynamics of six species of euphasiids in 1968 and 1969. Sarsia, 59, 67-84.

Lalli, C. M., 1970. Structure and function of the buccal apparatus of Clione limacina (Phipps) with a review of feeding in gymnosomatous pteropods. J. exp. mar. Biol. Ecol. 4, 101-118.

Marshall, S. M. \& Orr, A. P., 1962. Food and feeding in copepods. Rapp. P.-v. Réun. Cons. perm. int. Explor. Mer, 153, 92-98.

Matthews, J. B. L., 1969. Continuous plankton records: the geographical and seasonal distribution of Calanus finmarchicus s. 1 . in the North Atlantic. Bull. mar. Ecol. 6, 251-273. 
- 1973. Ecological studies on the deep-water pelagic community of Korsfjorden, western Norway. Population dynamics of Meganyctiphanes norvegica (Crustacea, Euphausiacea) in 1968 and 1969. Sarsia 54, 75-90.

— \& Pinnoi, S., 1973. Ecological studies on the deep-water pelagic community of Korsfjorden, western Norway. The species of Pasiphaea and Sergestes. (Crustacea, Decapoda) recorded in 1968 and 1969. Sarsia 52, 123-144.

- \& Sands, N. J., 1973. Ecological studies on the deep-water pelagic community of Korsfjorden, western Norway. The topography of the area and its hydrography in 1968-1972, with a summary of the sampling programmes. Sarsia 52, 29-52.

Orians, G. H., 1975. Diversity, stability and maturity in natural ecosystems. In: Unifying concepts in ecology. Ed. by W. H. van Dobben \& R. H. Lowe-McConnell. Junk, The Hague, $139-150$.

Ponomareva, L. A., 1966. Euphausiids of the North Pacific: their distribution and ecology. Israel Program for Scientific Translations, Jerusalem, $154 \mathrm{pp}$.

Rasmussen, R. E., 1971. Om biologien til Aglantha digitale (O. F. Müller) med bemerkninger om forekomsten av de övrige hydromeduser i Korsfjorden, Vest Norge. Unpubl. thesis, Univ. Bergen, 93 pp.

Russell, F. S., 1953. The medusae of the British Isles. Univ. Press, Cambridge, 530 pp.

Strickland, J. D. H., 1967. Between beakers and bays. New Scient. 33, 276-278.

Thomson, J. M., 1947. The Chaetognatha of south-eastern Australia. Bull. Coun. scient. ind. Res., Melb. 222, 1-43.

First author's address: J. B. L. Matthews

Institute of Marine Biology

University of Bergen

N-5065 Blomsterdalen

Norway 